\title{
PARTISIPASI DAN KEPUASAN PETANI TERHADAP KINERJA PENYULUH PERTANIAN DI KECAMATAN PALAS KABUPATEN LAMPUNG SELATAN
}

\author{
FARMER PARTICIPATION AND SATISFACTION ON EXTENSION \\ PERFORMANCE IN PALAS SUBDISTRICT, LAMPUNG SELATAN DISTRICT
}

\author{
Indah Nurmayasari*, Begem Viantimala, Dame Trully Gultom, \\ Helvi Yanfika, Abdul Mutolib \\ ${ }^{1}$ Program Studi Penyuluhan Pertanian, Fakultas Pertanian Universitas Lampung, \\ JL. Sumantri Brojonegoro No 1. Rajabasa Bandar Lampung \\ *E-mail: indahnurma1@gmail.com
}

(Diterima 14-01-2020; Disetujui 20-01-2020)

\begin{abstract}
ABSTRAK
Keberhasilan kegiatan penyuluhan dipengaruhi partisipasi petani sasaran. Selain partisipasi, kepuasan petani terhadap kinerja penyuluhan akan berkaitan dengan keberlanjutan penyuluhan dimasa mendatang. Penelitian ini bertujuan untuk menganalisis partisipasi dan kepuasan petani terhadap kinerja penyuluh pertanian di Kecamatan Palas Kabupaten Lampung Selatan. Penelitian dilakukan untuk di wilayah kerja penyuluhan Kecamatan Palas tang merupakan sentra pertanian khususnya padi sawah di Kabupaten Lampung Selatan. Penelitian dilaksanakan pada bulan MeiJuni 2019. Data yang dikumpulkan dalam penelitian ini terdiri dari data primer dan data sekunder. Analisis data menggunakan skala Likert. Hasil penelitian memberikan gambara bahwa partisipasi petani dalam kegiatan penyuluhan pertanian di Kecamatan Palas berada pada tingkat yang cukup tinggi. Keatifikan petani dalam kelompok tani dan mengusulkan kegiatan penyuluhan sebesar 56 persen, dan keterlibatan petani dalam memberi saran pembangunan kelompok tani dengan persentase 78 persen. Seluruh petani bergabung menjadi anggota kelompok tani tanpa adanya paksaan dari penyuluh atau pihak lainnya. Secara umum kepuasaan petani terhadap kinerja penyuluhan adalah cukup puas. Dari sembilan indikator, kepuasan petani terhadap gerakan massal diwilayah kerja mereka adalah yang paling rendah. Petani menilai puas terhadap cara komunikasi penyuluh pertanian. Petani puas dengan cara komunikasi penyuluh dan menilai kegiatan penyuluhan berdampak baik pada kegiatan penyuluhan pertanian.
\end{abstract}

Kata kunci: penyuluhan, partisipasi, kepuasan dan kinerja penyuluh.

ABSTRACT
The success of extension activities is influenced by the participation of target farmers. In addition to participation, farmer satisfaction with extension performance will be related to extension of sustainability in the future. This study aims to analyze the participation and satisfaction of farmers on the performance of agricultural extension workers in Palas District, South Lampung Regency. The study was conducted in the extension work area of Palas Tang District which is an agricultural center, especially lowland rice in South Lampung Regency. The study was conducted from May to June 2019. Data collected in this study consisted of primary data and secondary data. Data analysis uses a Likert scale. The results of the study provide a picture that the participation of farmers in agricultural extension activities in the District of Palas is at a fairly high level. Make farmers active in farmer groups and propose extension activities by 56 percent, and farmer involvement in giving advice on the development of farmer groups with a percentage of 78 percent. All farmers join to become members of farmer groups without coercion from extension workers or other parties. In general, farmers' satisfaction with extension performance is quite satisfied. Of the nine indicators, farmers' satisfaction with mass movements in their work areas is the lowest. Farmers are satisfied with the way the agriculture instructor communicates. Farmers are satisfied 
with the way the instructor communicates and assesses extension activities as having a good impact on agricultural extension activities.

Keywords: extension, participation, satisfaction and performance of extension workers

PENDAHULUAN

Pemberdayaan melalui penyuluhan pertanian diperlukan untuk mengubah pola pikir, sikap, dan perilaku guna membangun kehidupan dan penghidupan petani yang lebih baik secara berkelanjutan. Tidak bias dipungkiri hingga saat ini peyuluhan pertanian masih menjadi tumpuan dan andalan petani sebagai sumber informasi pertanian (Kartasapoetra, 2001).

Pertanian dan penyuluhan sedang menghadapi sejumlah tantangan untuk dipecahkan. Penyuluhan pertanian merupakan kegiatan penting dan strategis yang tidak dapat terpisahkan dari pembangunan di sector pertanian. Penyuluhan pertanian merupakan ujung tombak pembangunan di tingkat lapangan yang turut menentukan berkembangnya sistem usahatani yang dijalankan para petani atau kelompok tani. Salah satu indikator berperannya penyuluhan pertanian adalah perkembangan kelompok tani yang ditunjukan melalui kemampuan baik dalam hal teknis maupun manajemen usaha tani yang dijalankan.
Keberhasilan

pembangunan pertanian tidak bisa terlepas dari partisipasi masyarakat tani. Pembangunan yang dilaksanakan pemerintah tentunya bertujuan untuk mencapai masyarakat yang sejahtera sehingga posisi masyarakat merupakan posisi yang penting dalam proses pelaksanaan pembangunan yang dilaksanakan oleh pemerintah.

Partisipasi petani dalam mengikuti kegiatan di kelompoktani dipengaruhi oleh banyak faktor. Beberapa faktor yang berhubungan dengan tingkat partisipasi diantaranya adalah faktor-faktor yang berasal dari masyarakat itu sendiri, misal dari karakteristik sosial ekonomi petani sendiri (Hasyim, 2006).

Keberhasilan penyuluhan bukan semata-mata tergantung pada teknis penyuluhnya saja tetapi merupakan gabungan dari seluruh aspek mulai dari pelaksanaan tugas pokok dan fungsi penyuluh, kelembagaan, juga kondisi kelompok tani (Sumual et al. 2015). Dalam kinerja penyuluh ada 2 faktor yang mempengaruhinya. Faktor tersebut meliputi faktor internal maupun eksternal. Faktor internal dalam hal ini 
terkait dengan karakteristik penyuluh, sedangkan faktor eksternal terkait dengan sarana prasarana, kebijakan pemerintah, intensitas penyuluhan dan jarak tempat tinggal penyuluh yang dapat mempengaruhi perilaku kerja dan motivasi kerja yang tercermin pada kinerja atau job performance mereka (Suhanda et al. 2008).

Penelitian pendahuluan memberikan gambaran bahwa penyuluhan pertanian di Kecamatan Palas memiliki tujuan untuk meningkatkan kemampuan para petani dan anggotanya dalam keterampilan pola tanam, memilih bibit atau benih yang unggul serta meningkatkan mutu intensifikasi penerapan rekomendasi paket teknologi spesifik lokal, serta meningkatkan hasil produktivitas tanaman padi sawah. Kinerja penyuluh merupakan hasil usaha yang dilakukan dalam proses pencapaian tujuan, dari hasil kinerja dapat terlihat sejauh mana usaha yang dilakukan dalam proses pencapain tujuan yang dilakukan. Untuk mendapatkan kinerja yang tinggi seharusnya adanya sebuah hubungan dari apa yang telah di tentukan dengan apa yang terjadi di lapangan. Hal ini akan mengakibatkan kesesuaian antara tujuan dengan hasil yang di capai karena adanya komunikasi yang jelas dan rinci.
Penelitian ini bertujuan untuk menganalisis partisipasi dan kepuasan petani terhadap kinerja penyuluh pertanian di Kecamatan Palas Kabupaten Lampung Selatan.

\section{METODE PENELITIAN}

Penelitian dilakukan untuk di wilayah kerja penyuluhan di BP3K Kecamatan Palas Kabupaten Lampung Selatan. Lokasi dipilih secara sengaja dengan pertimbangan Kecamatan Palas merupakan sentra pertanian khususnya padi di Kabupaten Lampung Selatan. Penelitian dilaksanakan pada bulan MeiJuni 2019.

Data yang dikumpulkan dalam penelitian ini terdiri dari data primer dan data sekunder. Data primer diperoleh dari petani sampel melalui wawancara dengan menggunakan kuisioner yang telah dipersiapkan. Data sekunder diperoleh dari instansi terkait seperti kantor Badan Pusat Statistik Kabupaten Lampung Selatan dan Provinsi Lampung.

Informan penelitian adalah petani dalam yang tergabung dalam Gabungan Kelompok Tani (Gapoktan) Sidomakmur di Desa Bangunan Kecamatan Palas. Jumlah Informan sebanyak 9 petani dengan pendekatan snowball sampling. Metode analisis data menggunakan skala 
Likert dengan berbagai kelas (Widoyoko, 2012).

\section{HASIL DAN PEMBAHASAN}

\section{Gambaran Umum Informan}

Informan dalam penelitian ini merupakan petani aggota Gabungan Kelompok Tani (Gapoktan) Sidomakmur di Desa Bangunan Kecamatan Palas. Gambaran umum informan penelitian ditampilkan pada Tabel 1. Jumlah informan adalah 9 petani dengan rentang usia 50-62 tahun. Menurut Mantra (2004) usia produktif seseorang adalah dari umur 15 hingga 64 tahun sehingga secara umum petani yang menajdi informan masih dalam kelas usia produktif. Mulyasa (2003) dan Yanfika, Listiana, Mutolib, dan Rahmat (2019) mengemukakan bahwa perkembangan kemampuan berpikir terjadi seiring dengan bertambanya umur. Hal ini menunjukkan bahwa semakin tua umur seorang petani, akan semakin menambah pengalaman dalam berusaha tani. Komoditas usahatani dodominasi padi dan sebagian jagung. Jenis kelamin keseluruhan informan adalah laki-laki. Lama berusahatani informan pada rentang 20 hingga 30 tahun. Menurut penelitian Manyamsari dan Mujiburrahmad (2014), pengalaman usaha tani diklasifikasikan dalam kategori: (1) pengalaman baru adalah kurang dari 10 tahun, (2) pengalaman sedang berkisar antara 10 sampai dengan 20 tahun, dan (3) pengalaman lama lebih dari 20 tahun. Pengalaman berusahatani erat kaitannya dengan dengan kesejahteraan dan pendapatan petani (Rusdiana, Herdiansah, dan Yusuf, 2016).

Tabel 1. Gambaran informan penelitian

\begin{tabular}{cclcccr}
\hline No. Resp & Usia & $\begin{array}{c}\text { Jenis dan luas } \\
\text { usahatani }\end{array}$ & Kelamin & pendidikan & $\begin{array}{c}\text { Lama } \\
\text { bertani }\end{array}$ & $\begin{array}{c}\text { Pendapatan/ } \\
\text { bulan }\end{array}$ \\
\hline 1 & 53 & Padi (1 ha) & L & SMA & 25 & 1.000 .000 \\
2 & 50 & Jagung (10 ha) & L & SMA & 27 & 5.000 .000 \\
3 & 53 & Padi (1 ha) & L & SD & 30 & 1.500 .000 \\
4 & 51 & Padi (0,5 ha) & L & SMA & 20 & 1.000 .000 \\
5 & 50 & Padi (0,25) & L & SMA & 23 & 900.000 \\
6 & 52 & Jagung (5 ha) & L & SMA & 20 & 2.500 .000 \\
7 & 53 & Padi (1,5) & L & SMA & 25 & 3.000 .000 \\
8 & 62 & Padi (0,5) & L & SMP & 30 & 1.000 .000 \\
9 & 56 & Padi (0,25) & L & SMA & 22 & 1.500 .000 \\
\hline
\end{tabular}




\section{Gambaran Umum Kelembagaan Penyuluhan di Kecamatan Palas}

Undang-Undang No. 16 Tahun 2006 menyebutkan bahwa penyuluhan adalah proses pembelajaran bagi pelaku utama serta pelaku usaha agar mereka mau dan mampu menolong dan mengorganisasikan dirinya dalam mengakses informasi pasar, teknologi, permodalan, dan sumberdaya lainnya, sebagai upaya untuk meningkatkan produktivitas, efisiensi usaha, pendapatan, dan kesejahteraannya, serta meningkatkan kesadaran dalam pelestarian fungsi lingkungan hidup. Berdasarkan Peraturan Menteri Pertanian No. 16 Tahun 2008, penyuluh tersebut tergabung dan berwenang ke dalam organisasi pada satuan organisasi lingkup pertanian untuk melakukan kegiatan penyuluhan. Salah satu organisasi tersebut adalah Balai Penyuluhan Pertanian.

Balai Penyuluhan Pertanian (BPP) merupakan basis pelaksanaan penyuluhan pertanian di unit terkecil, yakni kecamatan. Berdasarkan Database Ketenagaan Penyuluhan Pertanian (Simluhtan, 2018), hingga tahun 2018 ketenagaan penyuluhan berasal dari penyuluh PNS sebanyak 25.247 orang, penyuluh THL- TBPP sebanyak 16.070 orang, penyuluh swasta sebanyak 103 orang dan penyuluh swadaya sebanyak 25.402 orang. Lebih lanjut, data tersebut juga disebutkan bahwa pada 6.998 kecamatan yang ada di Indonesia, hanya terdapat 5.643 unit BPP. Masih terdapat BPP yang membina lebih dari satu kecamatan, yakni 1.355 BPP. BPP sebagai wadah penyuluh mempunyai peran penting dalam membantu petani menjadi mandiri sehingga dapat mengatasi permasalahan yang dihadapinya sehingga meningkat derajat kehidupannya (Wahyuni, Helmi, Tanjung, dan Oktavia, 2018).

Kecamatan Palas merupakan salah satu sentra padi di Kabupaten Lampung Selatan. Pada tahun 2018 data keluarga petani di Kecamatan Palas terdapat sebanyak 11.292 keluarga petani. Ratarata usia keluarga petani di kecamatan palas berusia antara 21-60 tahun yang artinya masih banyaknya petani yang berada pada usia produktif. Pada umumnya masayarakat petani di Kecamatan Palas didominasi oleh suku Jawa, Sunda, dan Pasemah. Komunitas yang menjadi unggulan di Kecamatan Palas adalah ikan konsumsi air tawar, disusul dengan komuditas tanaman pangan seperti padi dan jagung. Rata-rata produktivitas produksi tanaman padi di Palas berkisar 7-9 ton per musim tanam. 


\section{Evaluasi Kinerja Penyuluh Pertanian}

Penyuluh pertanian harus mampu menempatkan petani sebagai kawan kerja dalam meningkatkan kesejahteraan petani, hal ini dapat dicapai melalui peningkatan pengetahuan dan keterampilan, namun yang paling penting dari tugas seorang penyuluhan pertanian adalah merubah sikap mental yang mendasari tingkah laku para petani menjadi lebih baik lagi agar dapat mewujudkan petani yang tangguh di era globalisai Subejo (2002). Evaluasi kinerja kinerja penyuluh pertanian ditampilkan pada Tabel 2.

Tabel 2. Evaluasi kinerja penyuluh pertanian di Kecamatan Palas

\begin{tabular}{|c|c|c|c|c|c|c|}
\hline No & $\begin{array}{l}\text { Penyediaan } \\
\text { saprotan }\end{array}$ & $\begin{array}{c}\text { Membantu } \\
\text { mencari } \\
\text { modal }\end{array}$ & $\begin{array}{l}\text { Membantu } \\
\text { pelatihan }\end{array}$ & $\begin{array}{c}\text { Kerjasama } \\
\text { dengan } \\
\text { pemerintah }\end{array}$ & $\begin{array}{c}\text { Kerjasama } \\
\text { dengan } \\
\text { poktan }\end{array}$ & $\begin{array}{c}\text { Menyusun } \\
\text { prokja }\end{array}$ \\
\hline 1 & 4 & 4 & 4 & 4 & 4 & 3 \\
\hline 2 & 4 & 3 & 4 & 4 & 3 & 4 \\
\hline 3 & 4 & 3 & 5 & 4 & 2 & 4 \\
\hline 4 & 5 & 4 & 4 & 5 & 2 & 5 \\
\hline 5 & 4 & 3 & 3 & 4 & 2 & 4 \\
\hline 6 & 5 & 4 & 3 & 5 & 2 & 5 \\
\hline 7 & 4 & 3 & 2 & 4 & 2 & 5 \\
\hline 8 & 4 & 3 & 4 & 4 & 2 & 4 \\
\hline 9 & 5 & 3 & 3 & 4 & 2 & 4 \\
\hline Jumlah & 39 & 30 & 32 & 38 & 22 & 38 \\
\hline Rata-rata & 4,33 & 3,33 & 3,56 & 4,22 & 2,44 & 4,22 \\
\hline
\end{tabular}

Evaluasi kinerja penyuluh pertanian adalah suatu kegiatan yang dilaksanakan secara sistematis dan berkesinambungan untuk mengukur tingkat keberhasilan berdasarkan parameter kinerja Penyuluh Pertanian dalam melaksanakan tugas dan tanggung jawabnya Serta Kinerja penyuluh pertanian dalam menyelesaikan tugas pokok termasuk beberapa indikator yang menghasilkan kinerja dengan kategori tinggi antara lain ialah menyusun program kerja, bekerjasama dengan pemerintah, dan penyedian saprotan untuk petani.

Hasil penelitian menunjukkan persepsi petani terhadap kinerja penyuluhan yang ada di Kecamatan Palas masih cukup memuaskan dengan rentang skor 2,44 hingga 4,33. Skor kinerja terendah adalah aspek Penyuluh membantu kelompok dalam menyusun program kerja dan rancangan peningkatan kualitas dalam pertanian dengan skor 2,44 (kurang). Kinerja penyuluhan tertinggi adalah aspek 
Penyuluh membantu anggota untuk mendapatkan saprotan yang baik dalam usahatani dengan skor kinerja 4,33 (baik).

Kinerja Penyuluh Pertanian dipengaruhi oleh banyak faktor. Menurut Polohindang, Sondakh, Lainawa, dan Tumewu (2016), kinerja penyuluh Pertanian dipengaruhi faktor internal dan eksternal. Faktor internal yang mempengaruhi kinerja Penyuluhan Pertanian meliputi : umur, pendidikan, pengalaman serta jumlah tanggungan keluarga. Faktor eksternal yang mempengaruhi kinerja Penyuluh Pertanian meliputi: sarana prasarana, sistem penghargaan, intensitas penyuluh serta jarak tempat tinggal penyuluh. Motivasi dalam kehidupan sehari-hari sangat memegang peranan penting karena dapat mempengaruhi sikap dan perilaku serta mempengaruhi kinerja penyuluh pertanian. Menurut Syafruddin, Hariadi, dan Wastutiningsih, 2013). Dalam Penelitian Sapar, Jahi, Asngari, Amiruddin, dan Purnaba (2012) menunjukkan bahwa faktor-faktor internal yang berpengaruh pada kinerja penyuluh pertanian adalah kompetensi, motivasi dan kemandirian.

\section{Partisipasi Petani dalam Penyuluhan}

Keberhasilan pembangunan pertanian tidak bisa terlepas dari partisipasi masyarakat tani Rusdiana, Herdiansah, dan Yusuf, 2016). Oleh karena itu dalam pelaksanaan pembangunan, partisipasi masyarakat merupakan hal yang sangat mempengaruhi keberhasilan proses pembangunan itu sendiri (Iwan, 2010). Partisipasi petani dalam dalam penyuluhan merupakan salah salah bagian penting yang akan berpengaruh terhadap tegaknya pembangunan pertanian dan tercapainya tujuan nasional. Partisipasi petani dalam kegiatan penyuluhan di Kecamatan Palas dijelaskan pada Tabel 3.

Berdasarkan Tabel 3 dapat diketahui bahwa keterlibatan petani dalam kegiatan penyuluhan pertanian yang diselenggarakan oleh Penyuluh Pertanian sebesar 44,00 persen, tingkat keatifikan petani dalam kelompok tani dan petani terlibat dalam mengusulkan kegiatan penyuluhan sebesar 56,00 persen. Keterlibatan petani dalam memberi saran pembangunan kelompok tani dengan persentase 78,00 persen, dan petani bergabung menjadi anggota kelompok tani tanpa adanya paksaan dari 
penyuluh atau pihak lainnya sebesar $\quad 100,00$ persen.

Tabel 3. Partisipasi petani dalam penyuluhan pertanian di Kecamatan Palas

\begin{tabular}{cccccc}
\hline No & $\begin{array}{c}\text { Ikut } \\
\text { Penyuluhan }\end{array}$ & $\begin{array}{c}\text { Aktif } \\
\text { Poktan }\end{array}$ & $\begin{array}{c}\text { Sukarela Bergabung } \\
\text { Poktan }\end{array}$ & $\begin{array}{c}\text { Memberikan } \\
\text { Saran }\end{array}$ & $\begin{array}{c}\text { Mengusulkan } \\
\text { Kegiatan }\end{array}$ \\
\hline 1 & 1 & 1 & 1 & 1 & 1 \\
2 & 0 & 0 & 1 & 1 & 0 \\
3 & 1 & 1 & 1 & 0 & 0 \\
4 & 0 & 0 & 1 & 1 & 0 \\
5 & 0 & 0 & 1 & 1 & 0 \\
6 & 1 & 1 & 1 & 1 & 1 \\
7 & 1 & 1 & 1 & 1 & 1 \\
8 & 0 & 0 & 1 & 0 & 5 \\
9 & 0 & 1 & 9 & 7 & 0,56 \\
\hline Jumlah & 4 & 5 & 1 & 0,78 & \\
\hline Rata - rata & 0,44 & 0,56 & & &
\end{tabular}

Keterangan: 0 (Tidak pernah terlibat), 1 (Terlibat)

Partisipasi petani dalam mengikuti kegiatan di kelompok tani dipengaruhi oleh banyak faktor. Beberapa faktor yang berhubungan dengan tingkat partisipasi diantaranya adalah faktor yang berasal dari masyarakat itu sendiri, misal dari karakteristik sosial ekonomi petani sendiri (Hasyim, 2006). Menurut Putri, Anwarudin, dan Sulistyowati (2019), faktor-faktor yang berhubungan dengan partisipasi petani dalam kegiatan penyuluhan adalah luas lahan, tanggungan keluarga dan kegiatan penyuluhan. Karakteristik sosial ekonomi petani yang berhubungan secara nyata dengan tingkat partisipasi petani adalah pengalaman bertani, umur, dan frekuensi mengikuti penyuluhan (Sitopu, Fauzia, dan Jufri, 2014).

\section{Kepuasaan Petani Terhadap Kinerja Penyuluh}

Kepuasaan kinerja adalah salah satu aspek psikologis yang mencerminkan perasaan seseorang apresiasi terhadap pekerjaann seseorang. Kepuasan petani terhadap kegiatan penyuluhan pertanian dapat diartikan sebagai kepuasan petani sebagai klien, dengan asumsi bahwa kegiatan penyuluhan adalah produk pelayanan yang diberikan oleh sebuah organiasasi yaitu kepuasan yang timbul karena adanya kesesuaian antara harapan yang ada dengan kondisi nyata yang ada pada kegiatan penyuluhan (Widyastuti dan Widiastuti, 2014). Melalui tingkat kepuasan masyarakat tani dalam memperoleh pelayanan dari penyuluhnya. Apabila penyelenggaraan penyuluhan tersebut dilaksanakan secara benar, kontinyu, dan konsisten, maka tingkat kepuasan petani juga akan tinggi yang 
berdampak pada peningkatan kualitas hidup petani (Arifin, 2015). Mengingat belum pernah dilakukannya pengukuran tingkat kepuasan di BP3K Palas, maka perlu dilakukan penelitian yang dapat mengukur tingkat kepuasan petani terhadap kinerja penyuluh pertanian. Kepuasaan petani terhadap kinerja penyuluh pertanian di Kecamatan Palas ditampilkan pada Tabel 4.

Tabel 4. Kepuasaan petani terhadap kinerja penyuluh pertanian di Kecamatan Palas

\begin{tabular}{|c|c|c|c|c|c|c|c|c|}
\hline No & $\begin{array}{c}\text { Kunjungan } \\
\text { Penyuluh }\end{array}$ & $\begin{array}{c}\text { Penyelenggaraan } \\
\text { Penyuluhan }\end{array}$ & $\begin{array}{c}\text { Kemampuan } \\
\text { Penyuluh }\end{array}$ & $\begin{array}{c}\text { Gerakan } \\
\text { massal }\end{array}$ & $\begin{array}{c}\text { Ketanggapan } \\
\text { Penyuluh }\end{array}$ & $\begin{array}{c}\text { Komunikasi } \\
\text { Penyuluh }\end{array}$ & $\begin{array}{c}\text { Pemberian } \\
\text { jasa }\end{array}$ & $\begin{array}{c}\text { Evaluasi } \\
\text { hasil }\end{array}$ \\
\hline 1 & 3 & 3 & 3 & 1 & 3 & 3 & 3 & 3 \\
\hline 2 & 2 & 2 & 2 & 1 & 2 & 3 & 2 & 2 \\
\hline 3 & 2 & 1 & 2 & 1 & 2 & 3 & 2 & 2 \\
\hline 4 & 2 & 2 & 2 & 1 & 2 & 3 & 2 & 2 \\
\hline 5 & 2 & 2 & 2 & 1 & 2 & 3 & 2 & 2 \\
\hline 6 & 2 & 2 & 2 & 1 & 2 & 3 & 2 & 2 \\
\hline 7 & 2 & 1 & 2 & 1 & 2 & 3 & 2 & 2 \\
\hline 8 & 2 & 2 & 2 & 1 & 2 & 3 & 2 & 2 \\
\hline 9 & 2 & 2 & 2 & 1 & 2 & 3 & 2 & 2 \\
\hline $\begin{array}{l}\text { Rata- } \\
\text { rata }\end{array}$ & 2,33 & 1,89 & 2,33 & 1 & 2,33 & 3 & 2,33 & 2,33 \\
\hline
\end{tabular}

Keterangan: 1 (Tidak Puas), 2 (Cukup Puas), 3 (Puas)

Berdasarkan Tabel 4 dapat di peroleh gambaran bahwa secara umum kepuasaan petani terhadap kinerja penyuluhan adalah cukup puas. Dari sembilan indikator kepuasan, kepuasan petani terhadap gerakan massal diwilayah kerja mereka adalah yang paling rendah. Sembilan informan menyatakan tidak puas pada indikator ini. Indikator lain memiliki penilaian cukup puas hingga puas terhadap kinerja penyuluh pertanian di Kecamatan Palas. Faktor yang mempengaruhi kepuasan petani terhadap penyuluhan adalah kualitas layanan yang nyata, keandalan, responseiveness, jaminan dan empati, adalah korelasi (Berkat dan Sunaryati, 2015). Selain itu faktor lain yang memperngaruhi kepuasan terhadap kinerja adalah kelengkapan dan kesiapan alat peraga, cepat tanggap dalam menghadapi masalah yang timbul, kecepatan dalam memberikan informasi terbaru terkait teknologi terbaru, memberikan bimbingan dan memecahkan masalah petani/ kelompok tani dalam mengambil keputusan guna menjalin kemitraan usaha dibidang pertanian, memberikan pelayanan dan menyelesaikan masalah secara tuntas (Limbong, Ayu, dan Iskandarini, 2019; Listiana, Effendi, Mutolib, dan Rahmat, 2019). Selain itu menurut penelitian Wijayanti, Paranoan, dan Kalalinggi (2015), kinerja penyuluh yang selalu cepat tanggap dalam menghadapi masalah petani, 
menyelesaikan masalah yang dihadapi secara tuntas dan pemberian informasi yang jelas dan mudah dimengerti oleh petani memperngaruhi kepuasan petani terhadap kinerja penyuluh pertanian.

\section{KESIMPULAN DAN SARAN}

Partisipasi petani dalam kegiatan penyuluhan pertanian di Kecamatan Palas berada pada tingkat yang cukup tinggi. Keatifikan petani dalam kelompok tani dan mengusulkan kegiatan penyuluhan sebesar 56,00 persen, dan keterlibatan petani dalam memberi saran pembangunan kelompok tani dengan persentase 78,00 persen. Seluruh petani bergabung menjadi anggota kelompok tani tanpa adanya paksaan dari penyuluh atau pihak lainnya. Secara umum kepuasaan petani terhadap kinerja penyuluhan adalah cukup puas. Dari sembilan indikator kepuasan, kepuasan petani terhadap gerakan massal diwilayah kerja mereka adalah yang paling rendah. Petani menilai puas terhadap cara komunikasi penyuluh pertanian. Petani puas dengan cara komunikasi penyuluh dan menilai kegiatan penyuluhan berdampak baik pada kegiatan pertanian petani di Kecamatan Palas.

\section{DAFTAR PUSTAKA}

[Simluhtan] Sistem Informasi Manajemen Penyuluhan Pertanian. 2018. [Internet]. Diakses pada 21 November 2018. [https://app2.pertanian.go.id/simluh 2014/gst/welcome.php].

Arifin, M. 2015. Analisis Tingkat Kepuasan Petani Terhadap Kinerja Pelayanan Penyuluh Pertanian (Studi Kasus di BP3K Kalibawang, Kab. Kulon Progo, D.I. Yogyakarta). Agrica Ekstensia. Vol. 9 No. 1: 40-49.

Berkat dan Sunaryati, R. 2015. Analisis Kepuasan Petani Terhadap Kegiatan Penyuluhan Pertanian di Kelurahan Kalampangan, Kota Palangka Raya Kalimantan Tengah. Jurnal Agribisnis, 9(1): 1 - 10.

Hasyim, H. 2006. Analisis Hubungan Karakteristik Petani Kopi Terhadap Pendapatan (Studi Kasus: Desa Dolok Seribu Kecamatan Paguran Kabupaten Tapanuli Utara). Jurnal Komunikasi Penelitian. Lembaga Penelitian. Universitas Sumatera Utara, Medan.

Iwan. 2010. Analisis Hubungan Karateristik Petani dengan Partisipasi Petani terhadap Program Pengembangan Agribisnis Jagung Hibrida pada Kabupaten Karanganyar.

http://iwansas.wordpress.com.

Diakses 13 April 2015.

Kartasapoetra, A.G., 2001. Tekhnologi Penyuluhan Pertanian. Bumi Aksara, Jakarta.

Limbong, M.S. Ayu, S.F. dan Iskandarini, I. 2019. Analisis Tingkat Kepuasan Petani Terhadap Kinerja Penyuluh Pertanian (Kasus: Kelurahan Tigarunggu, Kecamatan Purba, Kabupaten Simalungun). Journal on Social Economic of Agriculture And Agribusiness. 10 (2): 1-4. 
Listiana, I. Efendi, I. Mutolib, A. dan Rahmat, A. 2019. The behavior of Extension Agents in Utilizing Information and Technology to Improve the Performance of Extension Agents in Lampung Province. Journal of Physics: Conference Series, 1155 (012004): 1-9.

Mantra IB. 2004. Demografi Umum. Pustaka Pelajar. Yogyakarta

Manyamsari, I dan Mujiburrahmad. 2014. Karakteristik Petani Dan Hubungannya Dengan Kompetensi Petani Lahan Sempit (Kasus : Di Desa Sinar Sari Kecamatan Dramaga Kab. Bogor Jawa Barat). Agrisep, 15 (2): 58-74.

Mulyasa, 2002. Kurikulum Berbasis Kompetensi: Konsep, Karakteristik, dan Implementasi. Bandung (ID): Remaja Rosdakarya.

Putri, C.A. Anwarudin, O. dan Sulistyowati, D. 2019. Partisipasi Petani Dalam Kegiatan Penyuluhan Dan Adopsi Pemupukan Padi Sawah Di Kecamatan Kersamanah Kabupaten Garut. Jurnal Agribisnis Terpadu. 12(1): 103119.

Rosdiana, Y. Dedi Herdiansah, D. dan Yusuf. M.N. 2016. Hubungan faktor sosial ekonomi petani dengan pendapatan usahatani padi (Oryza sativa L) (Suatu Kasus di Desa Tanjungsari Kecamatan Rajadesa Kabupaten Ciamis). Jurnal Ilmiah Mahasiswa AGROINFO GALUH. 2(3): 201206.

Simanjuntak, O.V. Subejo. Witjaksono, R. 2016. Partisipasi Petani Dalam Program Gerakan Penerapan Pengelolaan Tanaman Terpadu Padi di Kecamatan Kalasan Kabupaten Sleman. Agro Ekonomi. 27(1): 20-27.
Sitopu, R. Fauzia, L. dan Jufri. 2014. Partisipasi Petani Dalam Penerapan Usahatani Padi Organik (Studi Kasus: Desa Lubuk Bayas Kecamatan Perbaungan Kabupaten Serdang Bedagai). Journal on Social Economic of Agriculture and Agribusiness. 3(4): 1-11.

Subejo. 2002. Penyuluhan Pertanian Indonesia: Isu Privatisasi dan Implikasinya. Agro Ekonomi, Vol 9 (2): 27-36.

Suhanda N, A..Jahi , B.Sugihen , D.Susanto.2008. Kinerja Penyuluh Pertanian di Jawa Barat. Job Performance of Agricultural Extension Agent In West Java Province. Jurnal Penyuluhan. Vol. 4 No. 2: 100-108.

Sumual N, O.Benu, G. Kapantow, M.Tarore M. 2015. Motivasi dan Kinerja penyuluh pertanian diwilayah kerja BP3K Kecamatan Amurang Timur. Jurnal Cocos. Vol. 6 No. 2: 01-21.

Wahyuni, S. Helmi. Tanjung, H.B. dan Oktavia, Y. 2018. Peran Balai Penyuluhan Pertanian (Bpp) Dalam Penyuluhan Komoditi Pangan (Studi Kasus Di Kabupaten Tanah Datar). Jurnal AGRISEP Vol. 18 No. 2 September 2019 Hal: 235 248

Widoyoko, S. Eko Putro. 2012. Teknik Penyusunan Instrumen Penelitian. Yogyakarta: Pusaka Pelajar.

Widyastuti, E. dan Widiastuti, N. 2014. Analisis Kepuasan Petani Terhadap Pelayanan Penyuluhdi Badan Pelaksana Penyuluhan Dan Ketahanan Pangan Kabupaten Magelang Tahun 2014. Jurnal Riset Manajemen Vol. 1, No. 2: 148 167. 
Wijayanti, N. Paranoan, D.B. dan Kalalinggi, R. 2015. Analisis Tingkat Kepuasan Petani Terhadap Kinerja Penyuluh Pertanian Lapangan (PPL) Di Kabupaten Kutai Timur. eJournal Administrative Reform, 3 (2): 263275.
Yanfika H, Listiana I, Mutolib A, and Rahmat A. 2019. Linkages between Extension Institutions and Stakeholders in the Development of Sustainable Fisheries in Lampung Province. Journal of Physics: Conference Series 1155 (01201), 19. 